\title{
FRONTERAS, OTREDADES: VARIACIONES SOBRE TEMA CERNUDIANO
}

Exilio y otredad, bajo ciertas condiciones, pueden funcionar como sinónimos. En los hechos, no de otro modo parece haberse comportado este binomio en parte considerable de la historia moderna: el exilio ha conllevado otredad, la otredad ha implicado exilio. Acaso no haya experiencia tan penetrante de la conciencia del otro (exterior) y de ser (/estar en el lugar de) el otro (hombre/ mujer, lenguas, culturas), como la del exilio forzoso.

La diáspora provocada por el desenlace de la guerra civil española tiene en Luis Cernuda a una de las figuras más ejemplares respecto de aquel binomio, y en Variaciones sobre tema mexicano $(1952)^{1}$ uno de sus textos más representativos. Por una parte, el poeta, a diferencia de la casi totalidad de sus colegas exiliados entonces, no emigró a un país hispanoparlante sino después de unos tres lustros de residencia en países anglosajones, durante los que vio reforzada, fuera ya de cualquier espejismo, la otredad que había comenzado a concienciar respecto de sí mismo dentro de España. Por la otra, ese cuaderno se ofrece como el registro conflictivo del reencuentro/desencuentro, en tierras mexicanas, con la patria propia; esto es, la forjada por la poesía.

No obstante esa tensión básica que promueve el crecimiento mismo del cuaderno, al par que deja huellas en todos sus niveles constitutivos, bastante usual ha sido su asociación con Ocnos (1ª ed., 1942), el otro cuaderno cernudiano de poemas en prosa. Por esta vía, al tratar de caracterizar de manera conjunta esos dos

${ }^{1}$ Todas las citas y referencias a Variaciones sobre tema mexicano se basan en la edición de Obra completa, t. 1: Poesía de Luis Cernuda preparada por Derek Harris y Luis Maristany, Siruela, Madrid, 1993, pp. 617-658. En el cuerpo del estudio sólo se registra entre paréntesis la paginación correspondiente. A menos que se indique lo contrario, son míos los subrayados de oraciones, sintagmas o plabras provenientes de ese cuaderno. 
cuadernos - los únicos de Luis Cernuda que, reconocidos como pertenecientes a su poesía, no integraron, sin embargo, La realidad y el dese $0^{2}$-, no han escaseado expresiones como: "obras de armonía", "elogio de una nueva conjunción de los componentes del Edén perdido" ", "visión edénica" ${ }^{4 . . ., ~ t r a t a n d o ~ a s i ́ ~ d e ~ a b a r c a r ~ c o n ~}$ un denominador común Ocnos y Variaciones sobre tema mexicano ${ }^{5}$. Lectores de intereses diversos en sus aproximaciones a ese corpus poemático, como Philip W. Silver, Jaime Gil de Biedma, o Derek Harris, por ejemplo, han coincidido en parte en esa tentativa unificadora insinuada por el propio poeta ${ }^{6}$.

Escritos en prosa los dos, y excluidos, además, de aquel volumen, sería difícil oponer una resistencia valiosa a esa tentativa: la comunidad entre ambos salta a la vista. Otra es en ellos, ciertamente, la naturaleza de la relación entre "la realidad" y "el deseo"; y, por otra parte, si en uno y otro se prefirió "la expresión poética en prosa" fue porque, poniendo a un lado ahora la fiabilidad de la opinión del poeta acerca del texto producido por él, ése era el vehículo que mejor se adecuaba al carácter de las experiencias a textualizar, o, cuando menos, servía para poner de realce una diferencia de ambos poemarios en prosa con respecto a las experiencias y perspectivas de los poemarios en verso.

Tanto es así que, según "L. C." en la referida nota editorial, aunque "no es de tradición española, ni apenas cultivado entre no-

2 F.C.E., México, 1980.

${ }^{3}$ Philip W. Silver, De la mano de Cernuda. Invitación a la poesía, Fundación Juan March-Cátedra, Madrid, 1989, p. 68.

4 Jaime Gil de Biedma, "Luis Cernuda y la expresión poética en prosa", El pie de la letra. Ensayos 1955-1979, Crítica, Barcelona, 1980, p. 329.

${ }^{5}$ Más ceñidas al cuaderno centrado en la experiencia mexicana, varias afirmaciones del profesor Derek Harris, uno de los más asiduos estudiosos de Cernuda, participan también de esa tendencia armonizadora; así, por ejemplo, al denominar el encuentro del poeta con México como "descubrimiento milagroso de un mundo apto para los sueños" o "experiencia casi mística del amor y la recuperación del mundo idílico de la niñez... donde por fin podía ser él mismo con toda fidelidad" (La poesía de Luis Cernuda, Universidad, Granada, 1992, pp. 136, 138). Afirmaciones estas cuyo sentido retoma en la introducción al t. 1 de la Obra completa de Cernuda: "el largo periplo del poeta desterrado termina con la residencia en una tierra hecha a la medida de sus sueños, donde se establece el acorde en el que se armonizan el hombre y el mundo" (p. 79).

6 "A ella (la tercera edición de Ocnos) le hubiera gustado añadir, separados, pero bajo la misma cubierta, los poemas en prosa que constituyen el librito $\mathrm{Va}$ riaciones sobre tema mexicano, análogos quizás en género y expresión a los de $O c$ nos", dijo el autor de ambos en una nota que acompañó parcialmente la nueva edición de este último (ibid., t. 1, p. 826). 
sotros [los escritores españoles], el género literario a que se llama poema en prosa..., su forma se impuso fatalmente... como adecuada y necesaria para sus recuerdos... y para sus nuevas experiencias" (p. 826). O sea, del mismo modo que otras "experiencias" requirieron del verso o del versículo para su puesta en texto, éstas de Ocnos y Variaciones... demandaron el "poema en prosa" como "su forma" "adecuada y necesaria"7.

Semejante insistencia en la necesidad y aun inevitabilidad de esa variante de la poesía moderna para textualizar sus "nuevas experiencias", termina por atraer la atención sobre la variante misma. ¿Qué especificidades de ésta la tornarían, de manera tan fatal, "adecuada y necesaria”? Según Jesse Fernández

los requisitos formales, estilísticos y emotivos que se reconocen como definitorios del poema en prosa [son] brevedad, densidad temática y expresiva, musicalidad, y, sobre todo, desprendimiento de la realidad objetiva mediante la creación de un ambiente altamente sugestivo8.

El "tono introspectivo" y ese reiterado "desprendimiento de la realidad material u objetiva" constituyen propiedades centrales en la caracterización propuesta por Fernández que se ofrecen como una primera tentativa de explicación del empleo de ese "instrumento lírico" en el caso de Cernuda. El escritor de Variaciones sobre tema mexicano no modificará los presupuestos mitopoéticos con que se acerca a esa otra cultura sino al influjo de las resistencias, de los desvíos que ésta ejerce sobre aquéllos; situación que tiene una de sus marcas textuales más notorias precisamente en el "tono introspectivo" (o ensimismamiento) resultante del difícil proceso de autoconocimiento y asunción de sí por parte del poeta-viajero. Semejante proceso, con los desdoblamientos que conlleva, tiende a prevalecer sobre cualquier otra oscilación reflexiva de los textos.

${ }^{7}$ Contrástese esta idea de la inexistencia de una tradición española del poema en prosa con la que sostiene al respecto JaIme Gil de Biedma, en el ensayo citado supra, nota 4. Por su parte, Pedro Aullón de Haro parece compartir más la opinión de Cernuda cuando afirma que a este poeta "corresponde... la elaboración de dos obras de poema en prosa que son modelo y eslabón artístico definitivamente recuperado para la literatura contemporánea española”, La poesía española en el siglo xx (hasta 1939), Taurus, Madrid, 1989, p. 253. De cualquier modo, aquel dato de la inexistencia de tradición (o tradiciones) conviene fijarlo: no será la única vez que aparezca en la revisión a que aspiran estas notas.

${ }^{8}$ El poema en prosa en Hispanoamérica. Del Modernismo al Vanguardismo. (Estudio y antología), Hiperión, Madrid, 1994, p. 33. 
La conflictividad que Jesse Fernández asocia con el poema en prosa (cf. pp. 37, 38, 73), tanto en su morfología misma como en su comportamiento histórico, ofrece otro rasgo que conviene tener en cuenta al tratar de explicar las implicaciones derivables de su empleo por Cernuda. No ha de ser casual que Ocnos y Variaciones.... aparezcan como respuestas a fuertes conmociones espirituales/sociales en la trayectoria del poeta: la pérdida de una España tras la derrota del bando republicano en la guerra civil y el comienzo del exilio en países de hábitos muy dispares a los de aquélla, en el caso de Ocnos; y la impresión de reencuentro con $s u$ España en México, "cuando casi no creía en mi tierra", en el caso de Variaciones...

A no dudarlo, ambos cuadernos delimitan hitos, similares a fallas tectónicas, en el recorrido autoconformador (de concepciones y prácticas) del poeta. Diríase como dos momentos de recuento y reorientación en esa trayectoria; aunque esto sea tal vez más visible en el cuaderno correspondiente a la experiencia americana (cara confirmadora y siempre otra de su España), cuando el poeta, más seguro de sí y estimulado por su ideal de amor recién hallado, decide abrirse a las nuevas posibilidades que adivina tras su reencuentro con la lengua propia — que es también la de su poesía"hablada en torno" suyo. Aun con semejante diferencia, no convendría desestimar aquellos rasgos en la consideración de Ocnos.

De lo que se trata, entonces, no es de negar una evidencia, sino de matizarla en atención a requerimientos de la especificidad misma de Variaciones..., el macrotexto —entre los dos de poesía en prosa- que más se resentiría con la extensión indiscriminada de expresiones reforzadoras del motivo armonía o armonización ${ }^{9}$. Precisamente, el movimiento doble entre la (aparente) constatación de esa armonía (conciliación, consonancia, acuerdo) durante sus residencias en tierras mexicanas y la creciente conciencia de su dificultad/precariedad para sostenerse en los propios textos, constituye uno de los rasgos medulares de este conjunto que tal caracterización dejaría fuera.

${ }^{9}$ En su libro Cernuda y el poema en prosa (Tamesis, London, 1984), el crítico James VAlender ya alertaba contra lo que parece haber adquirido visos de toda una tendencia, al afirmar que "por demasiado tiempo Variaciones se ha ido interpretando como celebración del supuesto regreso de Cernuda al Edén de sus sueños" (p. 120). Este libro de Valender, particularmente en sus apartados finales (pp. 109-121), ha resultado un interlocutor provechoso, por sus adelantos y sugerencias, para el propósito que enseguida declaro. Comentarios del propio Valender a la lectura del artículo — que agradezco- seguramente lo han favorecido. 
A rastrear y comentar algunas marcas textuales de las fisuras, de las brechas (/interferencias) o puntos de tensión en ese mapa de pretendida armonía se ceñirán las anotaciones (variaciones también) que siguen. Precisamente es eso lo que intento designar bajo el término otredades: los nudos donde ese proyecto (ideológico) inicial varía, es desplazado, sufre resistencias. Entre aquellas marcas, las que más me han interesado son las que giran, develando siempre al emisor discursivo, en torno a 'el otro', a las otredades. La relevancia - y el sesgo dado aquí a ese aspecto- se perfila tan pronto se comprueba que el protagonista-emisor de Variaciones... es un sujeto que se constituye en la frontera: con 'el otro' en que se escinde durante la puesta en texto, con 'el otro' que encuentra (o descubre retrospectivamente) a su paso..., en fin, con los varios tipos de otros entre los que se mueve en su viaje de conocimiento/asunción de sí.

\section{UN CENTRO EXCÉNTRICO: SITUACIÓN DE FRONTERAS}

"Tras de cruzada la frontera..." (p. 625).

"Apenas pasada la frontera..." (p. 629).

"Al cruzar el cancel..." (p. 644).

“...pasados los mares..." (p. 648).

“...cuando en el avión de regreso..." (p. 652).

“...al cruzar la frontera...” (p. 654).

Muchos son los indicios textuales de esa conciencia como para pasar sin más junto a ellos. El protagonista-emisor se constituye, finalmente, en esos desplazamientos entre un espacio (tiempo) correspondiente a la "realidad" en la acepción cernudiana ("tierras anglosajonas", "la trivialidad y el vacío de las tierras de donde venías", "los protestantes", "tierras puritanas", ...) y otro espacio (tiempo) epifánico ('México' [España/Andalucía]) ${ }^{10}$, sintetizado en la metáfora de la resurrección: “...casi te habías olvidado de que estabas vivo..." (p. 629); "Igual que si una losa te hubieran quitado de encima, vivías como un resucitado" (p. 652). Continua es esa conciencia de la frontera: "al otro lado de la frontera" (p. 629), "al otro lado de este continente" (p. 632), "gente de otro pue-

${ }^{10}$ Datos de interés sobre la prehistoria y algunas implicaciones de esta asociación pueden hallarse en el epígrafe "España, Sansueña, México" (cap. 3) del estudio del profesor D. HARrIs, citado supra, nota 5. 
blo distante" (p. 634), que a su vez comporta una concienciación del otro.

Mas, como prueba de la movilidad, del desplazamiento que signa su constitución como sujeto — con la escisión aneja-, "allá" y "aquí" no tienen valoraciones fijas, porque "allá" y "aquí" pueden designar igualmente uno u otro espacio. Depende del punto de vista textual que asuma el emisor/poeta, condicionado a su vez por el lugar (tiempo) de la escritura, para que se concrete la referencialidad de aquéllos y, asimismo, su valoración (connotativa).

Los 31 textos de Variaciones..., según la cronología de Harris y Maristany, fueron producidos entre febrero y noviembre de 1950; por lo que el lugar (tiempo) de su escritura habría sido, en lo fundamental, Estados Unidos (Mount Holyoke College, Massachusetts) ${ }^{11}$. Más importante todavía, para el propósito de este análisis, es reparar en la movilidad de los puntos de vista seguidos en el conjunto y, asimismo, en la variable distancia entre la vivencia y su rememoración (otra vivencia) escrita.

Si el emisor/poeta se ubica a sí mismo fuera del espacio 'México', "allá" señala una meta, la patria del deseo; si dentro, "allá" designa entonces un espacio en el que no se es (o no se siente ser) a plenitud, a excepción de los casos en que "allá" remite a un tercer espacio (tiempo) afectivo-familiar, apenas referido en unos pocos textos: 'España/Andalucía', evocado por el estímulo de las vivencias "aquî" ('México').

${ }^{11}$ Resulta interesante observar, en relación con el período de producción de Variaciones..., primero, que es otra la fecha declarada por CERNUDA en su "Historial de un libro (La realidad y el deseo)": "el librito en prosa Variaciones sobre tema mexicano [lo] comencé a escribir durante el invierno de 1949 a 1950" (Obra completa, t. 2: Prosa I, 1994, p. 655). Esta declaración acortaría en dos meses el lapso de tiempo transcurrido entre esa primera estancia en México (agosto-septiembre de 1949) y el momento de la textualización promovida por ella. Desde luego, la cronología de Harris y Maristany, basada a fin de cuentas en anotaciones textuales del poeta, no perdería validez por esta causa, y aun sería conciliable con aquel otro dato si se considera la posibilidad de que el poeta hiciera apuntes y primeros bocetos de algunos de esos textos en la fecha por él indicada y que se consagrara a la realización de un cuaderno con los textos así producidos sólo después, al año siguiente. En lo que concierne a las fechas de producción de cada texto por separado que ofrece esa cronología conviene reparar - es mi segunda observación- en que hay dos grandes fechas en torno a las cuales se concentran todos ellos: febrero-marzo (18 textos) y octubrenoviembre (13 textos). Conocer este dato y los textos correspondientes a cada una de esas grandes fechas productivas facilita una mejor percepción del doble movimiento característico del libro, entre la fuerza armonizadora y la que conciencia su precariedad, sus resistencias. 
Así, por ejemplo, mientras que en "Los ojos y la voz" se contrasta favorecedoramente el "aquî" ("México': "lenguaje delicado", "ojos a los que asoma el alma") con el "allá" ("Muchos años viviste entre gentes de ojos apagados y de voz inexpresiva"), e igualmente en "Dignidad y reposo" (en lo que concierne a los distintos modos de usar el cuerpo); en "La acera", en "Mercaderes de la flor", en "La concha vacía", en "Centro del hombre" y en algunos otros que hacen de ésta la variante mayoritaria, el "allá" (o "allî") está marcado favorablemente en tanto espacio confirmador/realizador del deseo. Otros textos, como "Un jardín", "El patio" o "El regreso", ejemplifican el caso en que el "aquí" ('México') propicia la evocación de un "allá" (España/Andalucía).

Acaso más interesante resulte esta constitución del sujeto en la frontera de los espacios (tiempos) entre los que se desplaza por sus efectos sobre la práctica escritural(/enunciativa) de éste. Escindido él entre esos espacios (uno, "ajeno", de estar por "necesidad"; otro, del "gusto", del "afecto"), el lugar de la enunciación/escritura también da muestras de tal escisión: "por unos días hallaste en aquella tierra tu centro" (p. 652), constata ya fuera del "centro", salido de él.

Veamos. Llegaste ayer y te vas mañana. ¿Vale la pena de recapitular este olvido tuyo instintivo del trabajo y ese sobresalto tuyo instintivo al recordarlo? (p. 638).

Los espacios se permean a través de la memoria (escritura). Ahora es el "trabajo" distintivo de uno el que perturba la placidez ("trabajo de vivir") encontrada en el otro.

Notablemente concentrado aparece este rasgo en expresiones como "estas otras tierras" o "este otro lado", en las que, junto con la superposición de esas orientaciones referenciales divergentes, aflora la conciencia del emisor de hallarse fuera del que sería idealmente su centro. ¿Y dónde se sitúa el emisor de un enunciado como éste: "Nada quedaba allá de la trivialidad y el vacío de la vida en las tierras de donde venías"? (p. 629).

Sea con respecto al espacio matriz de "la lengua [española]" —que es, además, el originario suyo-, sea con respecto al espacio epifánico, la excentricidad (o la provisionalidad de esa suerte de centro excéntrico en que parece situarse) es una marca de esta escritura que, además de (pro) moverla, incide sobre sus diversos planos constitutivos con su estela de disfrute sensual en cada uno, como lo ilustran las minuciosas recreaciones de paisajes e interio- 
res ("Un jardín", "La gruta mágica”, ambos, por demás, antológi$\cos$ ), o el asedio moroso de ciertas experiencias interpersonales ("Dúo", "Músicos rústicos"). Ejercida casi toda ella en un contexto lingüístico/espiritual sentido como ajeno (o provisional, en caso de sentirlo favorable), la escritura se ofrece como medio de re-vivir agradables (re) encuentros ["Pronto, pronto. Antes que te olvides, recuerda ..."] ya lejanos (/precarios) en el espacio (tiempo), sea con la "lengua... hablada en torno", con "la infancia perdida", o con el amor ${ }^{12}$.

Esta escisión, este desplazamiento entre espacios signados contrariamente, conlleva y termina por sacar a primer plano un problema de definición ética que el poeta de Variaciones... encara en no pocos de sus textos. "Lo nuestro", en particular, es paradigmático en ese sentido:

El primer contacto con aquel ambiente, que es tu ambiente, fue difícil después de tantos años. Sólo veías ya su desolación y su miseria, contra las cuales querías protegerte negando cuantas posibilidades, a pesar de todo, pudieran surgir tras ellas. Mas sobrepasado el primer movimiento de rencor atávico, comenzaste a entrever, a recobrar algo bien distinto (p. 629).

El espacio epifánico tiene esa ineludible desventaja: "desolación", "miseria"; percibida con mayor agudeza cuando se procede de algún espacio próspero, confortable, como las "tierras anglosajonas". La oposición entre confort material y plenitud espiritual queda así delineada, y el poeta no oculta la indecisión que le asaltó ante "el primer contacto" con ese espacio enriquecedor en lo espiritual, pero pobre, quizá muy pobre, en la dimensión materialeconómica. Por otra parte, como se hará evidente en otros textos, el mercantilismo (/utilitarismo) que favorece también la repulsa del poeta hacia "aquellas tierras" no está todo lo ausente que él quisiera de estas otras.

Rebasada esa mala impresión inicial, el poeta baraja una solución que le permitiría beneficiarse de las ventajas distintivas de uno y otro espacio: reunir "espíritu y riqueza", conciliar las fuentes del sustento material y del espiritual ${ }^{13}$. Hasta que su concien-

12 Hay que recordar, al respecto, que tras su regreso de ese primer viaje a México en septiembre de 1949, pasaron algunos meses (¿dos, tres, cuatro?) antes de que Cernuda comenzara a poner en texto las experiencias asociadas con ese viaje.

${ }^{13}$ En varios otros textos reaparece esta preocupación de cariz eticista. Así, 
cia (ética), situada frente a ese dilema insoluble de momento, le marca la pauta hacia la autodefinición: "Piensa sólo, si lo que te importa es el espíritu, adónde debes inclinar tu simpatía” (p. 629).

Sintomáticamente, la iniciativa en esa decisión corre a la cuenta, no de la razón, sino del instinto. El poeta no se engaña: no es su ser entero el que lo inclina hacia México. De manera explícita esta conciencia reflota en "El pueblo": "Esto que en ti simpatiza con la gente del pueblo es lo que de animal hay en ti: el cuerpo, el elemento titánico de la vida ..." (p. 635); y en "La imagen", al recononcer el poeta que "mucha parte de [él] no pued[e] compartir el fervor [religioso] de estas criaturas" (p. 633). Pero, como sostendrá en su defensa ya en el cierre del cuaderno: "si en la vida no hiciéramos más que cosas razonadas, mal andaríamos" (p. 657). Sobre esta base se insinúa un conflicto entre lo que él llama "afinidad instintiva" (p. 644) — que no es sino el deseo de (poder) abandonarse del todo a ese hallazgo confirmador-y la conciencia de sus límites, de sus resistencias.

Un sutil ejemplo de esto puede leerse en "El mercado", poema correspondiente a la etapa final de producción del cuaderno. En él, el deseo de integración/asimilación del poeta-viajero ("pasasteis un día de mercado por aquel pueblecillo", p. 645) recorta su silueta sobre la conciencia de su imposibilidad, de su diferencia: "sintiéndote intruso...". La aproximación de la "escena real" contemplada a otra de índole artística: "En grupos quietos por la mayor parte, silenciosos también, más que escena real te parecieron pintura de una muchedumbre"; que es precisamente lo que lo lleva a detener su mirada (también artística) sobre tal escena, si estimula su textualización, no propicia la integración deseada. El acercamiento modelizador de esa escena a un específico "lienzo de algún pintor sevillano clásico", tampoco es suficiente. El texto, entonces, se erige por el reverso del deseo frustrado que constata. Su presencia es, simultáneamente, su pretexto fallido: la otredad del sujeto enunciador suyo con respecto al "cuadro" en el que deseaba figurar de todos modos.

por ejemplo, en "El pueblo" se atribuye al tú (ese otro sobre el que recae el tono interpelativo del sujeto enunciador) la creencia en que "la abundancia daña" (p. 37); mientras que en "Propiedades" se intenta desplegar esa idea al postular uno de sus personajes - Albanio, proveniente de Ocnos- que la no tenencia de propiedades asegura la fidelidad del alma a su origen, la conservación de su alta identidad primera. Éste, sin embargo, no parece caer nunca en la cuenta de que mientras él tiene la opción de renunciar a sus bienes, Choco, su ideal y contraparte muda, no la tuvo. 
Tal asociación, de notorio carácter estetizante, entre la muchedumbre y un cuadro pictórico, y el consiguiente paso a la integración del poeta en ese su cuadro, sirve para poner de realce la conciencia de la precariedad o provisionalidad de la satisfacción de aquel deseo:

Sintiéndote intruso, y nostálgico de abandonar tan pronto el lugar te dirigiste con una pregunta a una de aquellas figuras. Mas era un pretexto; un pretexto para entrar, para quedar sutilmente en el cuadro con ella. Lo mismo que el personaje ausente, que sólo en el lienzo, esfumado y circunstancial, al fondo de él, en un espejo, así quedaste tú allí, actor elusivo y testigo invisible, reflejado en unos ojos (loc. cit.).

"Intruso" aun sin entrar y "nostálgico" antes de haberse ido, el poeta se muestra aquí muy consciente de su condición excéntrica, de su desplazamiento continuo sobre la frontera, incluso con respecto al espacio donde creerá haber hallado por fin su "centro"14. Su integración a éste, entonces, no es, porque no puede ser, completa: aquella condición conlleva la permeabilidad recíproca de los espacios entre los que se mueve su escritura, su memoria.

De ese delicado cierre de "El mercado" en que el arte (verbal) convoca como intertexto al arte (visual) para cumplir su cometido, importa que se repare, además, en la dependencia del poeta-viajero de la palabra ("una pregunta", no correspondida) y de los ojos "para entrar, para quedar" en ese espacio epifánico de "la lengua", de la identidad (amor, vida), de la poesía. Ésta, que deviene finalmente medio (y modo) único no tanto "para entrar [y] para quedar" en él como para constatar la precariedad de ese deseo, ha sido definida poco antes - en "Ocio"- por la conjunción de la palabra y la mirada: "La mirada es un ala, la palabra es otra del ave imposible" (p. 639). Casi tanto como el calificativo "imposible", de virtual aplicación a cuanto sea asociable aquí con la simbólica "ave", cuenta en esa definición la complementariedad esencial advertida entre "un ala" y "otra".

Variados son los modos, como se habrá notado, de figurar 'el otro' / 'los otros', las otredades, en Variaciones..., sin que sea uno mismo en todos los casos el grado de conciencia que de ellos manifiesta el emisor/poeta. Mientras que en "Recapitulando", por ejemplo, se agudiza esa conciencia del "otro [México] que fue duramente devastado", o sea, del otro país "devastado", mas no sepultado dentro

14 "Centro del hombre", si bien es anterior a "El mercado" por su datación, está ubicado mucho después en la secuencia de Variaciones... 
de éste; en "Propiedades" esa conciencia, si es que la hay ${ }^{15}$, se debilita en extremo con respecto a Choco, personaje que ni siquiera llega a constituirse en un yo-para-sí, por su mudez, o silenciamiento.

En este caso específico no se trata sólo de que ese personaje no hable en todo un texto construido sobre un modelo dialogístico ${ }^{16}$, sino que lo que de él hablan los demás no pasa de la autoproyección de algún otro personaje o — como ejemplifica el narradordel rodeo, del circunloquio. Ilustrativo al respecto es su recurso a los símiles -bastante frecuentes, por demás, en todo el cuaderno- para introducir a ese personaje: "como animalillo familiar" (p. 647), "como idolillo oscuro" (p. 648), con lo que ello implica de superposición de una realidad más o menos distante a otra que se intenta develar por ese medio; $y$ al diminutivo, que, junto con la disposición afectiva de tendencia protectora, devela cierta orientación empequeñecedora de la realidad del personaje.

Creo que no hay resistencia, sin embargo, en admitir que entre todos esos variados modos de figurar 'el otro' en Variaciones..., el más llamativo, el que primero atrapa la atención, es el del protagonista-emisor básico de todo el cuaderno. Este personaje (desdoblado), se sitúa, simultáneamente, en la fuente y en la destinación de ese discurso y - lo que acaso contribuya más a singularizar esa su ubicación escindida - tiende a deplazarse, como salido de foco, con respecto a su imagen previa a través de los diversos componentes del conjunto. "Ahi no hablaba la persona a quien llaman por mi nombre" (p. 658).

\section{"TÚ", INTERLOCUTOR Y OTRO DEL EMISOR}

Homólogo en algún sentido del desgajamiento experimentado por el emisor con respecto a España (su tradición literaria) en vir-

${ }^{15}$ La datación (octubre-noviembre de 1950) y colocación de un texto como "Propiedades" en Variaciones... (mucho más próxima al final que al comienzo) constituye otra prueba de la tensión irresuelta de las fuerzas/tendencias divergentes que coexisten en todo el cuaderno, durante el proceso de su constitución y, asimismo, el de su lectura. En la tendencia que parece seguir el cuaderno, en su ciclo de producción y en su secuencia, hacia una creciente problematización de los presupuestos del poeta, "Propiedades" desentona.

16 Comparable por esto con "Recapitulando", en éste, a diferencia del caso platónico de "Propiedades", el esquema dialógico parte de la aceptación de las varias desarmonías o asimetrías a las que el sujeto escindido no ha estado ajeno durante el recorrido textual previo. 
tud de su "amor" — rasgo diferencial— hacia "estas otras tierras" es ese desdoblamiento (descentramiento) suyo en la dimensión comunicacional de los textos.

Indicios de una escisión del yo revela, ya en "El tema", su inclusión en el "nosotros" identificable con "los españoles" y "España" — de donde se reconoce originario- al mismo tiempo que su enunciación/escritura explicita su ubicación personal en "estas otras tierras", otras en relación con aquel espacio que, si en este texto se tiene como centro, en otros posteriores se considerará también otro respecto de éstas.

Empero, él no es el único otro de ese sujeto colectivo denominado "España". En ese mismo texto, al tratar de conciliar como actitudes de un mismo sujeto "nuestra evidente indiferencia nacional, si no desvío, hacia estas tierras, con... la obra obtenida por los españoles en ellas" (p. 622), el autor que simultáneamente está tratando de ordenar/conciliar los proyectos (textos) coexistentes en Variaciones... considera la posibilidad de una heterogeneidad interna en aquel sujeto: "unos pocos" realizaron (o habrían realizado) esa memorable "obra", "frente a la hostilidad de otros y la indiferencia de la mayoría" (p. 622).

"Obra", "hostilidad", "indiferencia": tales son las actitudes (o frutos de actitudes) de sesgo universalizante en torno a las cuales se concentra esa heterogeneidad o diversificación interna del sujeto "España". Esta delimitación importa en la medida que se postula como la explicación de esas actitudes inconciliables de "España" con respecto a América; y, además, porque facilita el esclarecimiento de la situación personal del escritor en la trayectoria de ese vínculo entre culturas.

De las tres actitudes enumeradas a propósito del sujeto colectivo, el escritor que — como se retomará más adelante- anda en busca de una tradición para su personal empresa, rescata para sí, principalmente, dos: la "indiferencia" o falta de curiosidad en una primera etapa de su vida, disculpable si "nada revivía ante [su] imaginación... el acontecimiento maravilloso, obra de un puñado de hombres" (p. 622); y — cierto que de manera algo vergonzante- la "obra" que celebra y con la que va a identificarse una vez despertada su curiosidad ("interés"-"simpatía"-“amor") hacia "estas otras tierras" por azares de "la vida".

Tan significativo como esa explicación conciliadora, que trata, asimismo, de esclarecer el comportamiento de un sujeto individual (el escritor) con respecto a América sobre la base del comportamiento cuasi histórico del sujeto que lo abarca ("nuestra na- 
ción"), resulta el cambio que, justo en el fragmento textual en que el emisor pasa a hablar de sí mismo, se produce en el estatuto comunicacional del texto: de la primera persona plural en los pasajes en que habla de España, a una segunda persona singular en el pasaje en que particulariza su propia actuación personal ante esa especie de encrucijada: "En tu niñez y en tu juventud, ¿qué supiste, si algo supiste, de estas tierras, de su historia, que es una con la tuya?" (p. 622).

Junto con el sesgo autorreflexivo que introduce esa segunda persona aparece un rasgo que va a ser relevante en extremo para las sucesivas "variaciones": la interpelación a sí mismo por parte del emisor, con la distancia emotiva, y ética sobre todo, que ello supone ${ }^{17}$.

Este sujeto de la enunciación no va a hablar de sí mismo en primera persona singular, ni en tercera - como fue tan frecuente en Ocnos-, sino que va a enmarcar todo su discurso respecto de una segunda autorreferencial, develadora de una tensión interna en la fuente de ese discurso, y creadora de tensión, asimismo, en el testigo obligado de ese incómodo desdoblamiento: cualquier lector.

Distante del idilio, esa relación entre el yo y el tú textuales, comprensible es que ese otro ente cuya actitud se prevé y modela desde el texto - el lector- llegue a sentirse algo incómodo de entrada, pues, por una parte, aquel desdoblamiento constriñe sus operaciones posibles a las de un testigo, y, por otra, se le hace difícil la (auto)identificación con alguna de las partes en conflicto ${ }^{18}$.

${ }^{17}$ López CaSANOva, y Alonso consideran entre los posibles aportes del empleo de ese modelo comunicacional, y a su vez explicarán "su amplia difusión y uso en la lírica contemporánea": 1) servir como "máscara del yo para desaparecer del primer plano poemático, y así disimular el intenso subjetivismo"; 2) "crea[r] una distancia interior o psíquica, un plano de lejanía, lo cual permite, en consecuencia, una mayor lucidez analítica de las vivencias"; y 3) propiciar "de algún modo un implicador más o menos directo del lector, dado el juego de ambigüedad y tensiones que la función apelativa crea en el poema" (Poesía y novela. Teoría, método de análisis y práctica textual, Bello, Valencia, 1982, pp. 154-155). Las implicaciones 2 y 3 me parecen de especial interés para el caso de Variaciones...

${ }^{18}$ De sumo interés considero la proximidad del estatuto comunicacional de Variaciones... al del monólogo dramático según lo caracteriza Stephen SummerHILL ("Luis Cernuda and the dramatic monologue", en The word and the mirror. Critical essays on the poetry of Luis Cernuda, ed. S. Jiménez-Fajardo, Associated University Presses, London-Toronto, 1992, pp. 140-165). Precisamente la escisión en un mismo discurso entre las perspectivas divergentes que coexisten en él y debido a ello, también en su lector virtual, es la propiedad del monólogo dramático —extensible a ese cuaderno- en la que más insiste. La peculiaridad básica de Variaciones... con respecto al monólogo dramático residiría en la ori- 
Yo se ha desdoblado en tú, un otro, de sí mismo: "Curiosidad, confiésalo, no tenías. Culpa tuya, sin duda; pero nada en torno podía tampoco encaminarla".

La confesión, cuyo modelo discursivo se insinúa más de una vez en todo el cuaderno, presupone privacidad, un único interlocutor investido de atributos soberanos más allá del cual no se extiende la dinámica dialógica entre la culpa (su reconocimiento) y la administración del castigo. De ahí aquella posición incómoda deparada al lector, ese tercero, ese indeseado en tal tipo de comunicación.

Conviene no perder de vista que tan reveladores indicios de fisuras (o cicatrices) aparecen ya en el primer texto del cuaderno, que es también el texto encargado de conceder una unidad ( a posteriori), más o menos homogénea, al conjunto que introduce; al par que fija los códigos y condiciones de la lectura. A pesar de esa orientación unificadora respecto de sí mismo, y del macrotexto que inaugura, "El tema" no logra escamotear su condición "anfibia" entre el adentro y el afuera (del texto), entre la "realidad" y la ficción, entre el autor que suscribe el cuaderno y el personaje que hace de sí mismo ese autor.

Muchos son los ejemplos que podrían aducirse en favor de este comentario sobre algunas de las implicaciones del estatuto comunicacional seguido en casi todo Variaciones sobre tema mexi-

ginal (y más tensada) dialéctica entre el yo y el tú presentes como actantes en el discurso, y correspondientes los dos a un mismo sujeto (escindido). De este modo, "the struggle between self and other, author and character" (p. 152) que concentra el emisor del monólgo dramático, en Variaciones... se despliega y dramatiza a los ojos del lector por medio de la interpelación del yo hablante a un tú identificable con las posiciones de (o atribuidas a) el yo cernudiado de textos anteriores a este cuaderno, y aun dentro del propio cuaderno, como lo ejemplifica la tendencia de algunos de sus componentes a la revisión de posiciones sostenidas en otros. Caso paradigmático al respecto brinda la relación intratextual de "Ocio" con "La lengua"; así, mientras que en éste su yo enunciador afirma que "la poesía, en definitiva, es la palabra" (p. 625), en aquél un yo distinguible del de "La lengua" revisa ese enunciado: "En otra ocasión has dicho que la poesía es la palabra. ¿Y la mirada?” (p. 639). Ese tú al que se interpela ahora parece identificable con el yo emisor en "La lengua". Y quien en "Recapitulando" pregunta: "¿No has creído hallar en esta tierra los mismos defectos ancestrales que en la tuya?" (p. 657), está retomando el "rencor atávico" (p. 629) que suscita el recuerdo de España ante la visión de un pueblo mexicano de la frontera. El sujeto enunciador de Variaciones... se desplaza con respecto a posiciones sustentadas en otros momentos por él, en su tenso proceso de (auto)conocimiento y asunción de sí. 
cano. De entre ellos me han resultado de particular interés los que apuntan hacia una (auto)corrección de los presupuestos (saberes acumulados e ideales) del escritor en su acercamiento a la realidad mexicana, esos que manifiestan una conciencia vigilante con respecto a la propensión armonizadora (mitificante) del poeta:

acaso la vida exija, para estar viva, ese abono ruin de miseria y tristeza, entre las cuales ella, como una flor crece acrisolada. ¿Sofismas? (p. 629).

Entre el pueblo y tú, no te engañes, percibes un espacio difícil de sal$\operatorname{var}($ p. 634).

Veamos. El mundo sensual, marino, soleado, donde por unas horas crees vivir, ¿̇es real? ¿ ¿No es un sueño inconcluso de tu juventud que todavía persigues a lo largo de la vida? Aunque ese mundo fuera real, ¿sería el tuyo propio? (p. 638).

Mírale, tú que te creíste poeta, y tocas ahora en lo que paran tareas, ambiciones y creencias (p. 638).

Estas muestras del doble movimiento que se verifica en la conciencia textual/discursiva de Variaciones... se inscriben también en lo que antes he tratado de caracterizar como desplazamiento sobre la frontera, y que comprende, desde luego, el lugar de su escritura misma. Deducible de esto es que para explicar la elección de ese modelo comunicacional haya que tener en cuenta el hecho de que casi todo el cuaderno se escribiera en los regresos de Cernuda a Mount Holyoke, contextualizado por un ambiente espiritual para él desfavorable, o marcado por la provisionalidad, caso de ejercerse la escritura en otros espacios. En esas condiciones de aislamiento, tal modelo, a la vez que se orienta a indicar incomunicación (o "ensimismamiento"), se ofrece como un medio de revivir-revisar las experiencias fundadoras de esa escritura, que también lo son de un autoconocimiento.

Escisión del sujeto, doble movimiento de la conciencia, desplazamiento sobre la frontera... son todas operaciones que descubren o introducen fisuras, puntos conflictivos, en el proyecto (armonizador, conciliador) inicial de Variaciones..., asentado fundamentalmente en una concepción afín de "la lengua". 
ENTRE LA TRADICIÓN DEL SILENCIO Y LA DEL SILENCIAMIENTO:

"LA LENGUA" DE LAS VARIACIONES...

En el texto inaugural de Variaciones... ("El tema") Cernuda resume sus pesquisas entre la tradición literaria española, clásica y moderna, en busca de la tradición particular de ese tipo de cuaderno; la que no encuentra, sin embargo, ni siquiera en dos de los escritores que por su ubicación temporal, por sus intereses personales y por el aire de familia que el emisor insinúa compartir con ellos, pudieron haberla iniciado: Mariano José de Larra y Benito Pérez Galdós:

Ni Larra ni Galdós, quienes, aunque tan diferentes, tenían una conciencia igualmente clara, se preocuparon nunca por estas otras tierras de raigambre española (p. 621).

Tal entrada, en la que no deja de resultar sintomática la reiterada negatividad $^{19}$, funge a la vez como conclusión de la búsqueda intentada: no existe dentro de la literatura española, desde el siglo XVII hasta el siglo xx, una tradición constituida en la cual insertar un cuaderno como Variaciones... El principal signo de esa tradición probable mas no hallada, según Cernuda, ha sido el silencio (fruto de la indiferencia), o el silenciamiento, a juzgar por el caso de Galdós, interesado en no enemistarse "con sus [virtuales] lectores de este otro lado" (p. 621). Y tanto una salida como la otra - silencio y silenciamiento- equivalen a una disfunción de esa "conciencia clara" que el emisor celebra en ambos escritores. Desde luego, tal conclusión devela a un Cernuda consciente de ese riesgo gravitante también sobre sus Variaciones..., como se explicitará luego en "Recapitulando", culminación del agudizado pro-

19 Al llamar la atención sobre "la naturaleza especial" de las oraciones colocadas al principio (incipit) y al final de los enunciados (/textos), BAjTín sostenía que ellas "poseen cierta cualidad complementaria", adicional respecto de sus intrínsecos valores semánticos, "porque se colocan en la posición limítrofe del cambio de sujetos discursivos" ("El problema de los géneros discursivos", en Estética de la creación verbal, trad. Tatiana Bubnova, Siglo XXI, México, 1990, p. 280). En este caso, la negatividad importa porque abarca toda una tradición que, en la opinión del poeta, debió de existir, y que, sin embargo, no existe. Ese comienzo equivale a un primer comentario tras la relectura de la tradición literaria española en busca de la específica tradición genérica que, dentro de ella, correspondería a ese cuaderno. De este modo, Variaciones... se asume en el umbral de una tradición. 
ceso de ajustes en el que se inscriben los textos correspondientes a octubre-noviembre de 1950.

El poeta, por su parte, va a reconocerse en el inicio - cierto que fatal, involuntario- de una tradición, o, acaso más exactamente, desprovisto de una tradición para la empresa que lo mueve. De la "indiferencia nacional", con su correspondiente silencio, se desgaja ${ }^{20}$ Cernuda para textualizar, llevado del "amor", las meditaciones suscitadas en su ánimo por el reencuentro suyo, y, con él, de España ( su España), en "estas otras tierras". De este modo, si a la "indiferencia" correspondió "el silencio", al "amor", acompañado de una "conciencia igualmente clara" que las de Larra y Galdós, corresponderá Variaciones sobre tema mexicano.

Curiosamente, en su texto introductorio del tema sobre el cual han de variar los restantes no se menciona a México, país, en todo caso, sobreentendido en los sintagmas alusivos a América: "estas otras tierras", "este otro lado" o "los americanos". Pero, ¿cómo aguardar la mención particularizada de ese país de "este otro lado" con el que asocia la disposición de amor hacia todo el conjunto, si ni siquiera "el tema" mismo a desplegar en ese texto ha sido declarado? Recuérdese que tras exponer el recorrido desde la "indiferencia" al "amor" cubierto por el sujeto individual y emisor discursivo, éste, como si tomara conciencia del no-cumplimiento de la promesa del título, comenta:

Mas un pudor extraño le dificulta su expresión a ese amor tardío. ¿Reconocimiento de su inutilidad? Pudor es, en todo caso, lo que en este punto, callándote ahora, te lleva a soslayar el tema (p. 622).

Luego, ¿se escamoteó el tema anunciado en el título del texto inaugural? En una porción considerable, sí. Precisamente las nueve décimas partes de ese texto se dedicaron a rastrear la ausencia de lo que equivaldría a "el tema" de estas Variaciones... en la tradición literaria española. Ausente en ella toda referencia memorable a "este otro lado" que no sea la no muy halagüeña de Cervantes, ¿cómo esperar, entonces, una huella de "amor", ese "amor"

${ }^{20}$ Desgajamiento, desgarramiento, desprendimiento, tales son las metáforas organicistas de que se vale Cernuda para explicar en "El tema" la separación o independencia de América con respecto a España, sentida así como un proceso contrariador de la unidad ideal de un organismo; metaforización ésta más evidente en el caso de las llagas de Larra/España. En los textos sucesivos el sujeto individual, desgajado de España en lo que concierne a aquella actitud de indiferencia, se encamina a remontar esa distancia, nadando contra la corriente. 
a que equivaldría la escritura? Claro que valdría también preguntarse si esa misma esquivez/reticencia no será el prometido tema sobre el que variarán, de modos diversos, los textos sucesivos al tiempo que lo moldean ${ }^{21}$. En cualquier caso, la tónica del cuaderno, el tipo de exposición que prevalecerá, así como la caracterización del sujeto enunciador por sí mismo y en la relación con su interlocutor, han sido adelantados ${ }^{22}$.

El "pudor", por una parte, y la inexistencia de una tradición, con la ausencia consiguiente de un público ya creado, por la otra, se ofrecen, de manera explícita e implícita, como primeros argumentos a tener en cuenta para entender el recurrente y tensador desdoblamiento del protagonista-emisor de las Variaciones...

Nuevamente, como en los inicios de su trayectoria poética, Cernuda constata (o cree constatar) la inexistencia de una tradición (y del correspondiente público) para la expresión de su $a m o{ }^{23}$. Cuando en "Historial de un libro..." Cernuda distinga

con respecto a la acogida que los lectores les dispensan, dos tipos de obras literarias: aquellas que encuentran a su público hecho y aquellas que necesitan que su público nazca; [por cuanto] el gusto hacia las primeras existe ya, [mientras que] el de las segundas debe formarse; [por lo que] creo que mi trabajo corresponde al segundo tipo (pp. 641-642).

${ }^{21}$ Por su parte, José de la Colina reconoce que "ese tema global se le escapa”. Y abundando sobre el título precisa: "Tema mexicano, y no México como tema... Si hay varios motivos de México en el libro..., no hay, sin embargo, un tema único perceptible. Lo que se puede decir es que se trata de un libro enamorado", "México: visión de los transterrados (en su literatura)", en El exilio español en México 1939-1982, F.C.E., México, 1982, p. 413. Esta última aseveración abona la idea de que toda oscilación reflexiva de los textos se subordina al propósito del autoconocimiento.

22 En el final de "Centro del hombre" se explicita nuevamente ese pudor, sólo que ya mezclado con una incómoda nota de autoconmiseración: "Una vez más guardabas tu emoción para ti (¿para quién otro, que no seas tú, puede tener valor una emoción tuya?)" (p. 652).

${ }^{23}$ Philip W. Silver (en su libro citado supra, nota 3) advierte en relación con los inicios de la trayectoria poética de Cernuda que éste se halló entonces "con problemas de tradición literaria a la hora de poetizar su erotismo" (p. 28). Aunque esto, afirmado sin más y como de pasada, pueda resultar discutible, creo - en abono de esa tesis- que el problema de comunicación con el público lector evidenciado por Cernuda en los párrafos iniciales de "Palabras antes de una lectura" (1935) puede atribuirse, también, a una inseguridad del poeta con respecto a la existencia de la tradición y del público que corresponderían a su concepción/praxis de la poesía, en la que, como bien se sabe, nada secundario es el papel de Eros. 
Difícil será no vislumbrar, como un fundamento clave de tal conclusión, la experiencia de este cuaderno publicado seis años antes; sólo que ahora la inexistencia de una tradición (/público) se enmarca en otra - menos ceñida a su problemática individual-, a nivel de relación entre regiones/naciones, y de "visión [literaria] nacional".

Si en éstas no ha habido muestra que permita pensar en amor se entenderá que Cernuda tampoco encuentre muestra de ese amor (otro) que está en la base de su acercamiento escritural-afectivo al "tema mexicano". La inexistencia de una tradición se advierte entonces doblemente: ni tradición escritural que atestigüe siquiera interés por América, ni tradición para la expresión de ese específico amor, con sus respectivas inexistencias de público.

"Amor tardío", desde esta perspectiva, vale, tanto en el eje de los sujetos colectivos: la actitud de "los españoles" hacia "los americanos"; como en el de los sujetos individuales: una persona que siente que su amor no se corresponde con lo que las convenciones prescriben para un ser de su edad y sexo, ni acaso tampoco con la edad del objeto de ese amor. "Un pudor extraño", en ambas dimensiones, dificulta la expresión de ese amor. El desgarramiento o desprendimiento del sujeto individual y emisor discursivo con respecto al sujeto nación ("país", "tierra") y a ese otro suyo que designa con el pronombre "tú" lo afecta en las dos dimensiones. El fantasma de la transgresión/soledad gravita otra vez sobre el poeta cernudiano.

Esta cualidad inédita, no importa ahora si creada o constatada, emparienta, en alguna medida, la labor a emprender por el escritor de Variaciones... con la de sus predecesores del siglo $\mathrm{XvI}^{24}$,

${ }^{24}$ En "El mirador" la posibilidad no despreciada de este parentesco asoma nuevamente a la superficie textual: "Así debió también adueñarse de los viejos conquistadores, con el mismo dominio interior, como si ellos hubieran sido entonces, como tú lo eres hoy, los subyugados". Mientras que en "La lengua" se reconoce heredero de "quienes cuatro siglos atrás, con la pluma y la espada, ganaron para ella destino universal” (p. 626). Así, pues, al siglo xvi remonta el poeta el más antiguo antecedente visible de esa su tradición, así sea parcialmente. Sintomática, en este sentido, resulta la metáfora del barco empleada en el texto último de Variaciones... para designar la práctica que ha servido al poeta para acometer su personal empresa de reencuentro: "Como el niño que juega a lo que sueña, con su mismo ensimismamiento, he lanzado mi barco de papel, que ha de perderse de todos modos, a la corriente". Mientras que "los viejos conquistadores" dispusieron del barco como medio de transporte en sus viajes al "Nuevo Mundo", el poeta se ha valido de un "barco de papel", frágil y solitario, en el suyo de acercamiento. 
sólo que la "obra" de aquél se reduce a la dimensión lingüístico(mito) poética. Por eso, la importancia concedida a "la lengua", verdadero motivo articulador/sustentador de todas las "variaciones".

La caracterización que de ella se realiza en la primera de las "variaciones" resulta, por tanto, básica, como lo anticipa su propio lugar en la secuencia: 1) es ella, "la lengua", la que hace posible este viaje de reencuentro (y desencuentro) del poeta consigo mismo y de reconciliación con su tierra; 2) gracias a la 'universalidad' alcanzada siglos antes por ella y el espíritu que la informa, puede el viajero-poeta sentirse como en tierra propia lejos de su tierra; 3) una posición jerárquica le asegura a esa lengua su "destino universal" en relación con "los de las otras lenguas"; 4) el destino individual del poeta es inseparable del de su lengua, ...con sus correspondientes ventajas y desventajas.

Así caracterizada "la lengua", ¿no se estará propiciando su funcionamiento como "un marco del paisaje [cultura] admirable, [que lo limita] apenas para hacerlo accesible al ser humano [ajeno a ella]" (p. 626), según se explicita con otro propósito en "Miravalle" y se practica en "El mercado"? Polémica, sin duda alguna, es la primacía otorgada al "destino universal" de "la lengua [española]" por sobre cualquier otra. Ni siquiera identificando a "la lengua" con la poesía que ella parece transparentar disminuye el carácter polémico de tal comparación.

Lengua, identidad y poesía, si no como sinónimos, guardan entre sí una relación a modo de vasos comunicantes. De no menor interés en esa caracterización se torna la tendencia de "la lengua" a borrar diferencias, a acortar distancias, a (re)conciliar... dentro de su espacio propio, desde luego. Así, se entiende mejor que el espacio habitable por el poeta en armonía plena sea todo aquel (y sólo aquel) comprendido por su lengua natal, esa lengua que, finalmente, no es sino la de la poesía o asimilable por ésta:

algo anterior, no sabes qué, imagen venida cómo o por dónde, parecía haberte preparado para esta simpatía profunda, este conocimiento entrañable que a su vista en ti despierta (p. 632).

He ahí la "obra" de "la lengua" que en ella y por ella el poeta disfruta y renueva. ¿Qué otra cosa es sino "lo nuestro"? Contrastado con "las tierras de donde venías", evidentemente, "lo nuestro" designa un conjunto de valores y maneras de concebir la existencia que el emisor no ha hallado en aquéllas (las anglosajonas) y 
que, además, son comunes a su tierra originaria y a esa otra ( $m a l$ gré tout, siempre otra) que tanto se la recuerda. "Lo nuestro", entonces, se define frente a lo 'extraño'/inhóspito en términos de lengua, ciertas costumbres, paisajes, edificaciones y prácticas vitales; e incluye al 'yo' hablante y al "tú" en que el sujeto se desdobla, y, asimismo, por lo menos una dimensión de los seres oriundos de esa tierra evocadora de la primigenia del poeta. En sentido lato, "lo nuestro" es identificable con el dominio de la poesía, con todo lo que la favorezca, en la concepción de Cernuda, ocio, quietud contemplativa, desinterés, belleza de criaturas y paisajes... y, por supuesto, "la lengua".

De ahí que pueda distinguirse entre "nuestro" y "ajeno", como entre "nuevo" y "extraño": no denotan lo mismo. México (-América), por ejemplo, puede(n) ser sentido como "nuevo" por el viajero-poeta, mas no "ajeno" (del todo); mientras que las "tierras anglosajonas", por el contrario, después de los muchos años pasados en ellas, no son "nuevas" para él, pero sí "ajenas", "extrañas", en su hostilidad doble (lingüística y económica) a la poesía (en la concepción cernudiana). Comprensible - y hasta legítima-, por esta vía, se hace la euforia expresada por el poeta debido al reencuentro, fuera de sí, con su lengua, con su amor ${ }^{25}$.

Prontamente, sin embargo, comienza la constatación de los silencios, involuntarios unos y otros voluntarios, de esa lengua en la que se actualiza también una visión de mundo, una ideología; silencios que en gran medida devienen condición de posibilidad de aquel "destino", de aquella armonía, a los que no dejará de mostrarse sensible la conciencia ética del poeta. En torno a esta aguda fuente de tensión se debaten las "variaciones", entre la armonización de raigambre estética y la (auto-)reconciliación ética.

El poeta, hemos visto, celebra la "obra" por la cual ganó (¿̇o será mejor decir que confirmó?) su "destino universal la lengua [española]"; pero, una vez puesto a interactuar (o a meditar sobre los efectos de tal interactuación) con la dinámica propia de la realidad sociohistórica de México, comienza a intuir o concienciar la obligatoriedad de su movimiento en la frontera (otra vez, la fron-

${ }^{25}$ Como recordará el lector de Variaciones..., el poeta celebra en sendos textos (uno, "La lengua”; el otro, "El regreso") ese reencuentro, fuera de sí, con "la lengua [suya]" y con su amor. Mediante la supresión de la conjunción copulativa en el cuerpo del artículo intento insinuar la equivalencia entre ambos en Variaciones..., o, por lo menos, su no diferenciación precisa. "Lengua" y "amor", en este cuaderno, más que sinónimos, se condicionan recíprocamente, se necesitan uno al otro. 
tera) de esa lengua para sus operaciones cognitivo-expresivas con ella. De una parte, porque se siente llevado por el instinto (gusto, simpatía, amor, afecto) a la comunicación extra-verbal, pre-racional, entre cuerpos; comunicación ésa que, lejos de cualquier uso neutro o inocente, mucho favorece la posición que sustenta el principal usuario/beneficiario de esa lengua en el texto con respecto a esos otros ("cuerpos callados y misteriosos") cuyos "labios guardan silencio, pero cuántas cosas dicen los ojos, y qué bien las dicen" (p. 631): "Verdad es que la poesía también se escribe con el cuerpo" (p. 635).

Así lo explicita alguna vez ese privilegiado usuario de "la lengua". La "graciosa", la "pura" animalidad del cuerpo: ningún vehículo mejor para depurar de resonancias perturbadoras o 'feas' la palabra en el poema; ninguno mejor para alcanzar, por ella y en ella, la deseada armonía. (Significativamente, a esta conclusión se llega en un texto de título tan poco propenso a la armonía, por sus resonancias e implicaciones sociopolíticas, como "El pueblo".)

De otra parte, aquel movimiento en la frontera de "la lengua" escapa a la voluntad de su usuario por cuanto existe(n), en esa nueva "realidad americana" que es su objeto, cierta(s) zona(s) verdaderamente $\operatorname{otra}(s)$, que opone(n) resistencia al acceso de "la lengua" - "universal", no obstante-, por su incompatibilidad con la manera de ver/concebir el mundo inscrita en ésta.

El mundo, la "realidad", alcanzan hasta donde alcanza "la lengua”, la visión que ella condiciona, el espíritu que informa. Fuera de ese espacio iluminable/iluminado por "la lengua", todo puede sentirse ajeno, o percibirse como "extraño" o "extraordinario". La lengua/cultura de las "tierras anglosajonas" ejemplifica lo primero; la cultura (/lengua también, aunque no se mencione) de los nativos o indígenas ejemplifica lo segundo, la extrañeza.

Paradigma impar de esta extrañeza ofrece "La gruta mágica", uno de los poemas correspondientes a la etapa final de producción del cuaderno, a partir sobre todo de aquel momento en que al encontrarse "en un paraje inesperado y extraordinario" dentro de un recoveco en una iglesia, el emisor, autorreflexivo, se autocorrige:

¿Te encuentras? ¿No sería más atinado decir que te pierdes? Porque perdido estás; la realidad ha cesado y flotas en otro medio. ¿Cuál? (p. 641).

Los automatismos del lenguaje, las asociaciones fácilmente inducibles, constituyen obstáculos adicionales para la aprehensión/ 
explicación de una realidad (cultura) de por sí hostil a las demarcaciones gnoseológicas/ideológicas de "la lengua [española]". Muy significativo es que lo último y "más atinado" que se pueda (y se recomiende) decir sea el reconocimiento de la propia pérdida; más allá del participio (de pasado) perdido, parece como si se agotara la "universalidad'de "la lengua": "la realidad ha cesado y flotas en otro medio" cuya naturaleza se desconoce, se vuelve opaca, inaccesible, para (y desde) esa lengua.

Particularmente aguda se torna aquí la conciencia de los límites, de la frontera para el "destino universal" de esa lengua:

Paredes y techo, aunque tampoco es atinado hablaraquí de paredes o techo, cuando lo que te rodea, si a algo de este mundo [asegurado y aprehensible por esa lengua/cultura] se asemeja, sería a la tienda de un bárbaro guerrero asiático, se ahondan en una penumbra... (p. 642).

Más allá de ese otro por antonomasia (el "bárbaro") develador de una cultura que se concibe a sí misma como centro/norma se encuentra la otredad fatal de la cultura mexicana. Ella escapa incluso al extremo de lo otro a que puede llegar la imaginación de una cultura/lengua hegemónica: si a "algo de este mundo" construido/modelizado por la cultura/lengua española podría asemejarse la otredad interna o intrínseca de México sería - pues tampoco es seguro- la del "bárbaro".

La declarada resistencia de esa otra cultura sumergida en la cultura mexicana al "destino universal" de "la lengua [/cultura]" actualizada por el emisor discursivo vuelve a ponerse de manifiesto en la enumeración asindética de sustantivos sin artículos y de gerundios sin complementos que trata de aprehender/moldear el "caos" de elementos que se ofrece y resiste a su mirada:

En el dramático claro-oscuro, toda una fauna y flora ponderosa, alas, garras, tentáculos; troncos, tallos, hojas; muslos, vientres, fauces; cabelleras, corolas, plumas, vivo todo, pulula y serpentea, retorciéndose, encontrándose, anillándose, como formas brotando del caos (p. 642).

Fuera de la realidad constatable por "la lengua", fuera de su 'cosmos', se intuye el caos, o sea, lo que ella no aprehende, bien porque hasta ahí no llega su 'universalidad'; bien porque la realidad del caos preexiste (y persiste, acéptese o no) a la de "la lengua [esa]". De ahí que ni siquiera la acumulación de sinónimos, como 
antes tampoco aquella enumeración, baste al propósito expresivo de "la lengua":

Es un sabat, un aquelarre, un pandemonium, y sólo la reiteración monótona y variada de las palabras expresaría, intentaría expresar, esto que miras (p. 642).

Se trata, en fin, de una realidad sin analogía en el sistema de referencias propio del hablante: "no se concibe la mente que la meditara y planeara”. Especialmente perturbador es el efecto de esa realidad 'excedente' (o 'exceso de realidad') sobre la memoria mítica/mitificante del poeta, a la que, lejos de clarificar/depurar y permitir desplegarse, "aumenta la confusión”.

Manifestaciones tan extravagantes - para el poeta- de esa otra realidad (/cultura) si le desasosiegan percibidas por separado, le sobresaltan aun más en su convivencia con imágenes de la realidad del poeta incompatibles con aquélla, según él. Tales muestras de otredad, significativamente, han sido constatadas donde menos se les esperaba: en el interior de uno de los baluartes de la cultura española en México (-América) que se supondría menos vulnerable, una iglesia. Semejante alteración ("confusión”) de los presupuestos del viajero-poeta obliga a éste a reconocer la rediviva presencia y condición troncal de esa otredad sumergida, incluso con respecto a la cultura española:

¿No ha usurpado el símbolo a la creencia, el culto a la religión? Un culto mucho más remoto, en todo caso, es el que parece perdurar, a pesar de los símbolos familiares visibles (p. 642).

Reconocimiento éste que, si suscita conmoción en sí mismo, conmociona no menos por la refutación que supone de aquella idea sustentada en "La imagen" según la cual la religiosidad ("fe tan absoluta") característica de la cultura mexicana era "la obra más duradera de tu raza [esto es, la del poeta], entre éstos que tan de la tuya te parecen" (p. 633). Aunque no se aluda en éste a ese otro texto, "La gruta mágica" revisa en profundidad, y con la autenticidad que le concede su mayor inmediatez a la vivencia, aquella conclusión, en verdad peregrina, a la luz de la celebración que hace el poeta de la "obra" de su lengua en "estos otros pueblos al otro lado del mundo"26; y, además, porque él no ha estado im-

${ }^{26}$ Este caso de discrepancia de puntos de vista entre textos, que no es el úni- 
permeabilizado a la presencia de esa otredad, con independencia del trato que le otorgue a sus manifestaciones en cada caso.

Así, v. gr., en "Miravalle" el poeta no oculta una cierta voluntad de silenciamiento con respecto a "los ecos trágicos de leyenda y de historia" surgidos de la contemplación de un paisaje, en favor del disfrute de las sensaciones armoniosas suscitadas en él por éste ${ }^{27}$. En "Por el agua" parece resignarse a esa presencia y, sobre todo, a la idea de que ella es inaccesible para él. Revelador en extremo de una conciencia alerta respecto de esa otredad es el hecho de que la única vez que en ese texto se produce un desdoblamiento sea para cuestionarse acerca de su participación en el desconocimiento de América (México) y del lugar común que la declara "tierra nueva", en prueba de una total ignorancia o voluntad de olvido de la historia previa a su encuentro con las culturas europeas:

¿Tierra nueva? No sabes qué ecos de sabiduría extinta, de vida abdicada, yerran por el aire. Esos cuerpos callados y misteriosos, que al paso de sus barcas nos tienden una flor o un fruto, deben conocer el secreto. Pero no lo dirán (p. 630).

En situación parecida a la de ese lugar común el poeta intuye no pocas veces su sensación de armonía. Dentro del sujeto colectivo México se activa para "la lengua" / conciencia del poeta un otro, una otredad, que reflota, persistente, por más disfraces que le sobreponga "la banalidad contemporánea". Ese sustrato propio de la cultura mexicana hace tenaz resistencia al proyecto inicial de $\mathrm{Va}$ riaciones... de identificar a México con los personales presupuestos mitopoéticos de su autor; fisura o brecha ésta que la sensibilidad ética del escritor no es remisa en reconocer: "¿Estás realmente aquî́? ¿No es en tu imaginación donde ves a esta tierra?” (p. 654).

co en todo Variaciones..., pone una vez más de relieve las fluctuaciones que signan el cuaderno, así como la pertinencia de conocer las fechas de producción de cada uno de sus componentes. En este caso, un texto de octubre-noviembre (situado al final de la secuencia macrotextual) revisa y refuta una conclusión propuesta en otro de febrero (situado al principio de esa misma secuencia). Proponer, entonces, esos 31 textos como partes de un todo unitario (el libro), reforzado por la presencia de un texto introductorio general y otro a modo de epílogo, no deja de ser otro indicador de la fuerza armonizadora que coexiste en él con su creciente sensibilización ética.

${ }^{27}$ Similar es la disposición que muestra en "La imagen": "Poco importa el camino, las ramificaciones ancestrales que ayudaron para que tal resultado se alcanzara: dioses remotos idos, culto cruel extinto" (p. 633). 
Evidentemente, la filtración depuradora de la palabra a que propende Variaciones..., la abstracción de cariz universalizante hacia la que el poeta la orienta, no consigue escamotear, sin embargo, la resonancia sociohistórica ni el recorrido ideológico previo de la palabra. Respuesta, réplica ella a la interacción con circunstancias sociodiscursivas muy específicas, en esa palabra designativa de ciertos valores celebrados como 'espontáneos' o 'naturales' del espacio epifánico, resuena esa otredad suya. Casos como el de las palabras "pobreza", "dignidad", "oferta", "competencia”, "precio" ("Acaso el precio de estar vivo sea esa pobreza y duelo que veías en torno", p. 629), son notables al respecto.

Por más que el poeta tienda a depurar de resonancias desarmonizadoras la palabra que emplea, en ésta perviven ellas. Particularmente llamativa se hace esa tensión en torno al mercantilismo que el poeta rehuye y que encuentra, no obstante, en la cultura mexicana, si bien no tan agudizado como en "las tierras de donde [él] venía". En "El mercado", por ejemplo, la visión artística intenta superponerse a una escena eminentemente socioeconómica:

¿Quién compraba? ¿Quién vendía? Bajo la luz nublada de la mañana, esta escena... te parecía sin otro motivo que el de componer para la contemplación una pura imagen plástica (p. 646).

Y en "Mercaderes de la flor" esa superposición de ámbitos (y voces) concebidos como excluyentes se intenta ya desde el título. En este texto los vendedores de flores, "para [quienes] no hay últimos ni primeros" (p. 631), proponen su "hermosísima oferta" sin competencia entre ellos mismos. Por otra parte, la metáfora con la que el poeta celebra la pertinencia de tal ofrecimiento resume la dialogicidad conflictiva entre aquellos ámbitos (y voces) en el interior de cada término suyo: "la hermosura alimenta". Similares presupuestos dejan entrever la pregunta: “CComprenderían allí los industriales protestantes que la pobreza puede ser vocación orgullosa e intransigente?" (p. 631). Así, pues, si los estratos o zonas de la cultura mexicana de difícil acceso al poeta oponen resistencias al inicial proyecto armonizador, las muestras del mercantilismo que él rechaza lo hacen también, aunque con menos fuerza concienciadora.

La conciencia ética del poema de Variaciones... se ha mostrado sensible al "ruido" de esas varias otredades: el desdoblamiento mismo de su correlato textual, como en una "imagen ante el espejo", con la insatisfacción y el malestar — ante todo, consigo mismo- 
que también acusan, constituye su marca principal en los textos, y el núcleo tal vez de todas las otras. Con una notable historia de uso en la praxis poética cernudiana previa, ese desdoblamiento, enconado ahora en torno a las diferencias (renovadas en cada texto) entre la imagen preexistente del poeta y la (auto-)concienciación gradual del emisor, alcanza en Variaciones... uno de sus hitos de mayor funcionalidad.

Finalmente, de regreso a la idea cernudiana acerca del poema en prosa y su adecuación al tipo de experiencias a textualizar en este cuaderno, comentada apenas al principio de estas reflexiones, preguntaría si no constituye la elección de ese género, en este caso particular, otra muestra del desplazamiento sobre la frontera -que hemos visto en otras de sus instancias-, ahora entre dos soportes genéricos de posibilidades y concepciones distintas en (su) relación con la lengua, y en sus maneras de construir la realidad: la poesía (versal) y la prosa, o sea, la poesía en la prosa, y viceversa.

Osmar Sánchez Aguilera El Colegio de México 